\title{
Sistem Kontrol Atap Otomatis Tempat Penjemuran Berbasis Mikrokontroler Arduino UNO dan Node Sensor
}

\author{
Tesal Kobandaha $a^{*}$, Handy I.R. Moseya ${ }^{*}$, Verna A. Suotha ${ }^{*}$ \\ aJurusan Fisika, FMIPA, Unsrat, Manado
}

K A T A K U N C I
Node sensor, sistem kontrol,
atap otomatis.

K A T A K U N C I
Node sensor, sistem kontrol, atap otomatis.

\begin{abstract}
A B S T R A K
Telah dilakukan penelitian untuk simulasi dan realisasi node sensor system control atap otomatis tempat penjemuran berbasis mikrokontroler. Node sensor yang dibangun terdiri atas mikrokontroler ArduinoUNO yang dirangkai dengan beberapa sensor seperti sensor suhu dan kelembaban, sensor hujan, sensor cahaya, dan motor servo. Metode Penelitian yang digunakan adalah metode eksperimen yakni dengan merancang perangkat lunak dan membangun perangkat keras. Pembacaan sensor hujan dan sensor cahaya dijadikan penentu untuk menutup dan membuka atap otomatis. Kinerja node sensor telah dianalisis dan dibandingkan dengan alat ukur terstandar. Hasil pengujian menunjukan node sensor sistemkontrol bekerja sesuai yang diharapkan. Node sensor mampu menutup dan membuka atap secara otomatis pada kondisi hujan dan/atau gelap dan kipas dinyalakan saat kondisi kelembaban melebihi nilai ambang batas yang ditetapkan.
\end{abstract}

KE Y W O R S

Sensor node, control system, automatic roof.

\begin{abstract}
A B S T R A C T
Research had been conducted to simulate and realize an automatic roof control system for drying warehouse based on microcontroller and sensor node. The sensor node is consisted of Arduino UNO microcontroller that is strung together with sensors for temperature and humidity, rain sensor, light sensor and motor servo. The research method was experimental with designing the software and constructing the hardware. The rain sensor and the light sensors reading were fed to the microcontroller as an input to close and open the roof automatically. Sensor node performance then was analyzed and compared with the standardized instrument. The test result showed that sensor node was working as expected in which the sensor node can opened and closed the roof automatically when it was raining in the dark condition. Moreover, the fan was turned on when the humidity condition exceed the threshold value.
\end{abstract}

TERSEDIA ONLINE

05 Oktober 2018

\section{Pendahuluan}

Seiring berkembangannya teknologi yang begitu canggih membuat manusia terus berinovasi untuk mempermudah pekerjaannya. Hal ini menjadikan teknologi sebagai kebutuhan dan penunjang pekerjaan. Perkembangan teknologi menuntun manusia untuk berfikir kreatif agar dapat menciptakan alat - alat baru dan menjadikan pekerjaan menjadi lebih ringan (Alam dan Hamida, 2014).

Indonesia merupakan Negara beriklim tropis yang memiliki dua musim, yaitu musim hujan dan musim kemarau (Susandiet al., 2008). Adanya pemanasan global menyebabkan kondisi cuaca tidak bias diprediksi dengan akurat (Yongshuo et al., 2015). Saat musim hujan tiba, petani merasa khawatir saat menjemur padi di suatu tempat terbuka. Hal ini disebabkan karena kebanyakan petani masih mengunakan cara konvensional untuk menjemur. Penjemuran padi di tempat terbuka menyulitkan petani pada saat hujan akan turun (Golmohammadi et al., 2011). Cara penjemuran kovensional memiliki beberapa kelemahan, antara lain: petani harus menjaga hasil panen saat dijemur, harus diangkat ketika hari sudah sore dan sinar matahari tidak selalu konstan saat menjemur hasil

*Corresponding author: Jurusan Fisika FMIPA UNSRAT, Jl. Kampus Unsrat, Manado, Indonesia 95115; Email address: vernasuoth@unsrat.ac.id Published by FMIPA UNSRAT (2018) 
panen (Kurnia et al., 2016). Pengeringan padi menjadi tidak optimal sehingga terjadi pembusukan dan kualitas beras menurun (Nusyirwan, 2014).

Atap otomatis dirangkai dengan mengunakan alat mikrokontroler, sensor cahaya, dan sensor hujan, kelebihan dari mikrokontroler adalah sistem elektronik dapat menjadi ringkas, cepat dan didukung oleh perangkat lunak sehingga menjadi mudah untuk memodifikasi. Pembacaan sensor hujan dan sensor cahaya dapat menjadi masukan (input) kepada mikrokontroler untuk menutup dan membuka atap secara otomatis. Mikrokontroler dan sensor yang digunakan memiliki harga terjangkau dan mudah didapatkan. Mikrokontroler dengan mengunakan sensor cahaya terbukti dapat menutup atap secara otomatis (Nuryanto et al., 2017). Pada penelitan sebelumnya telah dilaporkan bahwa mikrokontroler telah digunakan untuk mengatur sistem rumah pintar (smart home system) yang berupa pengaturan cahaya (Smart Home Ligthting Control System), suhu (Smart Home Temperature Sensing System For Air Conditioner), serta sistem keamanan rumah (Mowad et al., 2014). Lwin et al., (2015) juga mengunakan mikrokontroler pada pintu otomatis dengan cara mendeteksi wajah mengunakan sensor, melakukan pengenalan wajah dan mengontrol pintu otomatis. Selain itu, mikrokontroler juga telah digunakan untuk mengontrol lampu jalan otomatis (Saad et al., 2013) dan pengembangan purwarupa node multi sensor pemantauan parameter cuaca (Mosey, 2017).

Pengunaan atap otomatis berbasis mikrokontroler dapat membantu petani untuk menutup atap saat hujan akanturun, sehingga petani tidak harus khawatir melakukan penjemuran di tempat terbuka.Dari penelitian sebelumnya, (Damastuti dan Syafi'i, 2016), dijelaskan bahwa atap otomatis dapat membuat petani tidak merasa cemas saat menjemur hasil panen. Jochem et al. (2009) telah mengusulkan suatu teknologi deteksi tentang atap otomatis dengan menganalisa radiasi sinar matahari. Teknologi tentang penelitian atap secara otomatis untuk keperluan pemanasan, pencahayaan, pendinginan, dan kelembaban telah didesain dan dikonstruksi, dapat membantu petani (Alausa dele dan Kolawole, 2013).

Pada penelitian (Hendriawan, 2015), (Suleman, 2010), (Mufida dan Abas, 2017), dan (Fuad, 2013). Telah mengembangkan atap otomatis berbasis node sensor dengan mengkombinasikan sensor-sensor seperti kelembaban, suhu, cahaya, dan hujan namun tidak merupakan kombinasi dari semua sensor yang disebutkan.

Pada penelitian ini telah dikembangkan sebuah node multi sensor yang merupakan kombinasi dari sensor kelembaban, sensor suhu, sensor cahaya, dan sensorhujan. Node sensor yang dibangun merupakan rangkaian sebuah pengontrol otomatis yang dapat membuka dan menutup atap secara otomatis, serta dapat menyalakan kipas angin untuk mengontrol sirkulasi udara tempat penjemuran.

\section{Material dan Metode}

\section{A. Material Penelitian}

Material yang digunakan dalam penelitian ini adalah:

\section{Arduino UNO R3}

Board mikrokontroler berdasarkan pada chip ATMega328. Board inimempunyai 14 pin I/O (6 di antaranya dapat digunakan sebagai output PWM), 6 input a

Analog, sebuah osilator kristal $16 \mathrm{MHz}$, koneksi USB, powerjack, ICSP header dan tombol Reset. Koneksi dengan komputer dapat menggunakan USB. Catu daya dapat menggunakan baterai atau adaptor. Bentuk Fisik Arduino UNO R3 ini dapat dilihat pada Gambar 1.

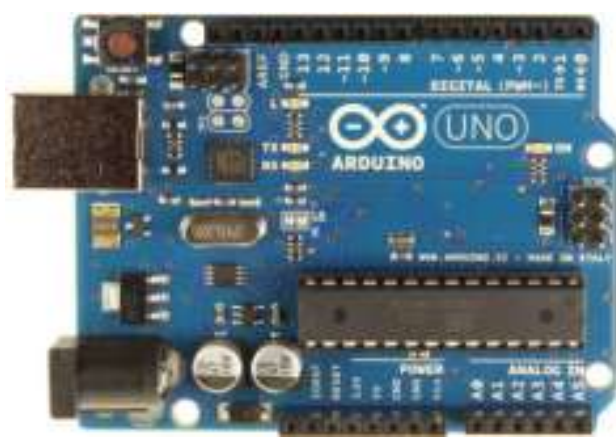

Gambar 1. Board Arduino UNO R3

\section{Sensor hujan}

Sensor ini bekerja berdasarkan prinsip kapasitif untuk mendeteksi tetesan air. Bentuk Fisik sensor ini dapat dilihat pada Gambar 2.

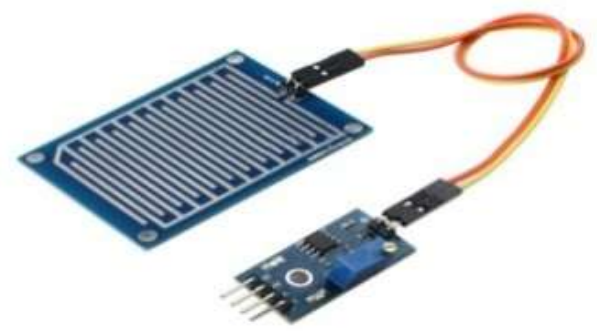

Gambar 2. Bentuk fisik sensor hujan

\section{Sensor Cahaya}

Sensor ini sering disebut sensor LDR (Light Dependent Resistor). LDR merupakan komponen dengan karakteristik resistor yang memiliki kepekaan terhadap cahaya. Bentuk Fisik sensor ini dapat dilihat pada Gambar 3. 


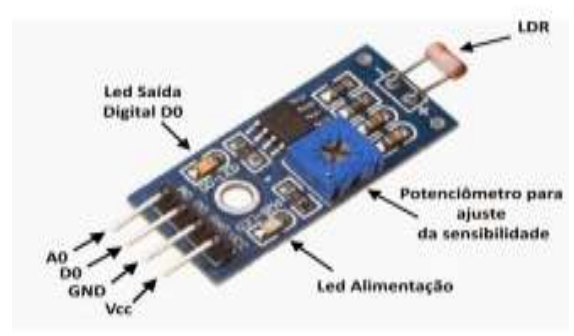

Gambar 3. Bentuk fisik sensor cahaya.

\section{Sensor Suhu dan Kelembaban}

DHT22 adalah sensor yang dapat mengukur suhu dan kelembaban udara. DHT22 memiliki keakuratan tinggi dan stabilitas yang baik ketika digunakan dalam waktu yang panjang. Bentuk Sensor DHT22 dapat dilihat pada Gambar 4.
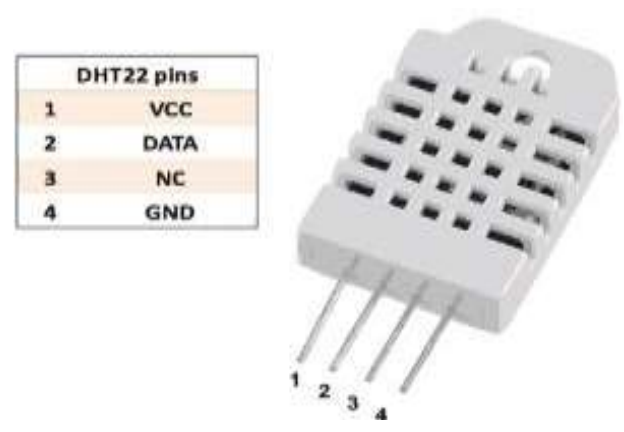

Gambar 4. Bentuk fisik sensor DHT22

\section{B. Metode Penelitian}

Metode pengembangan sistem yang digunakan dalam penelitian ini yaitu metode eksperimen dengan mendesain perangkat lunak dan mengonstruksi perangkat keras.

\section{DesainPerangkatLunak}

Desain perangkat lunak meliputi pemograman untuk masing-masing sensor. Diagram blok perangkat lunak dapat dilihat pada Gambar 5.

Perintah eksekusi program dapat dilihat secara jelas padaTabel 1 dan Tabel 2. Sensor hujan dan sensor cahaya diatur sebagai pemicu untuk membuka dan menutup atap sementara sensor suhu dan kelembaban diatur sebagai pemicu untuk menyalakan atau mematikan kipas agar terdapat sirkulasi udara pada tempat penjemuran.

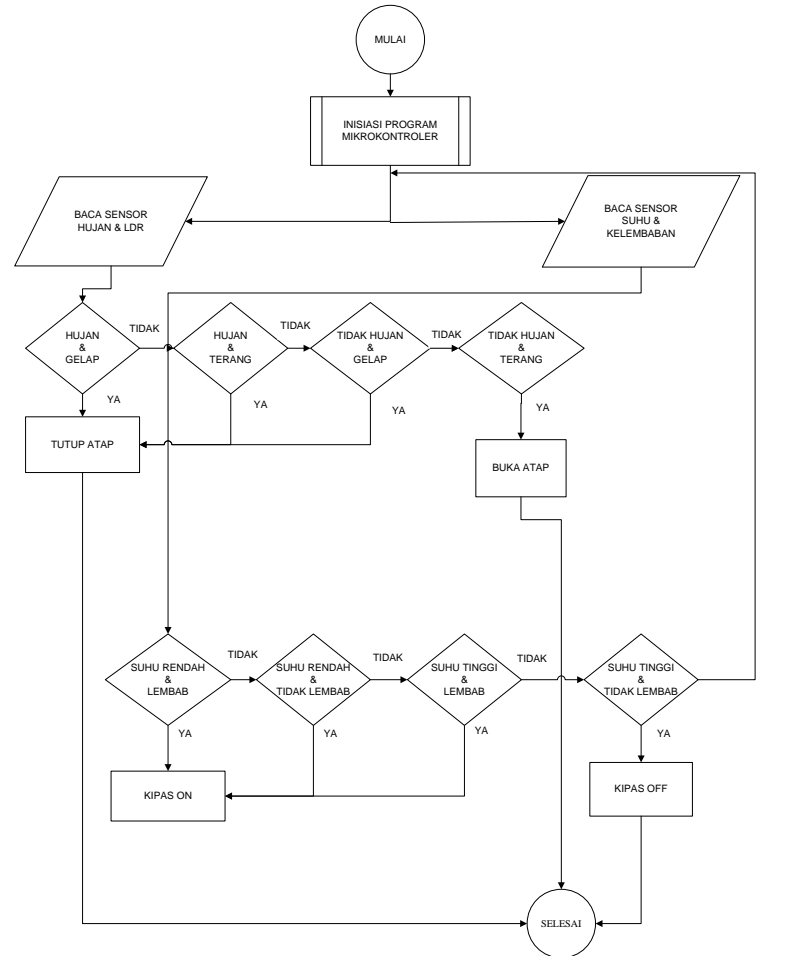

Gambar 5. Diagram Alir Perangkat Lunak

Kode program telah diatur untuk kondisi pembacaan sensor hujan, sensor cahaya, dan Sensor DHT22.

\section{Desain Perangkat Keras}

Desain perangkat keras meliputi mendesain tata letak sensor, merangkai modul-modul sensor dan motor servo kepengendali mikrokontroler. Hasil pembacaan masing-masing sensor menjadi input pada mikrokontroler untuk mengaktifkan dan menjalankan motor servo. Diagram blok perangkat keras dapat dilihat pada Gambar 6.

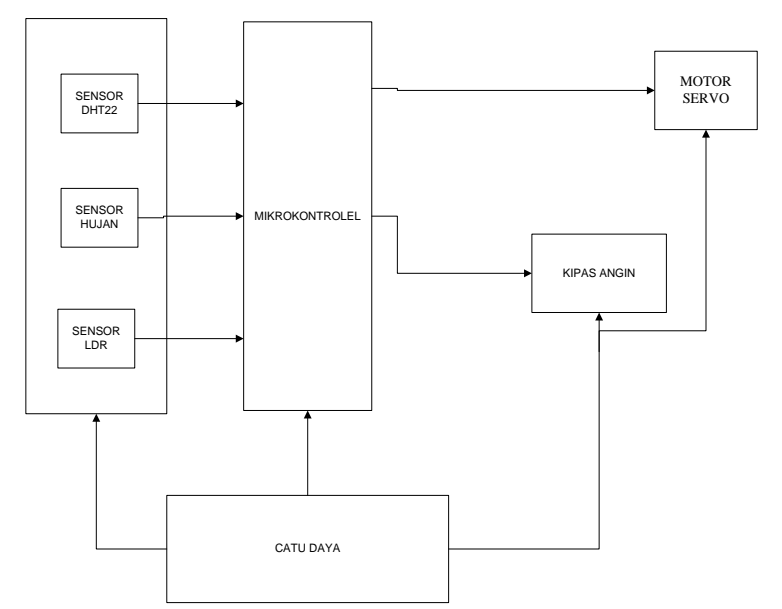

Gambar 6. Diagram blok perangkat keras

\section{Hasil dan Pembahasan \\ Pengujian sensor hujan}

Sensor hujan diuji dengan cara meneteskan air dengan menggunakan pipet keatas penampang sensor hujan. Setiap tetesan menghasilkan nilai pembacaan sensor yang berbeda. 
Hasil pembacaan awal ketika belum ditetesi air, ADC sensor menunjukan nilai 1021. Ketika terdapat satu tetes air nilai pembacaan ADC sensor berubah menjadi 939 (asumsi turun hujan).

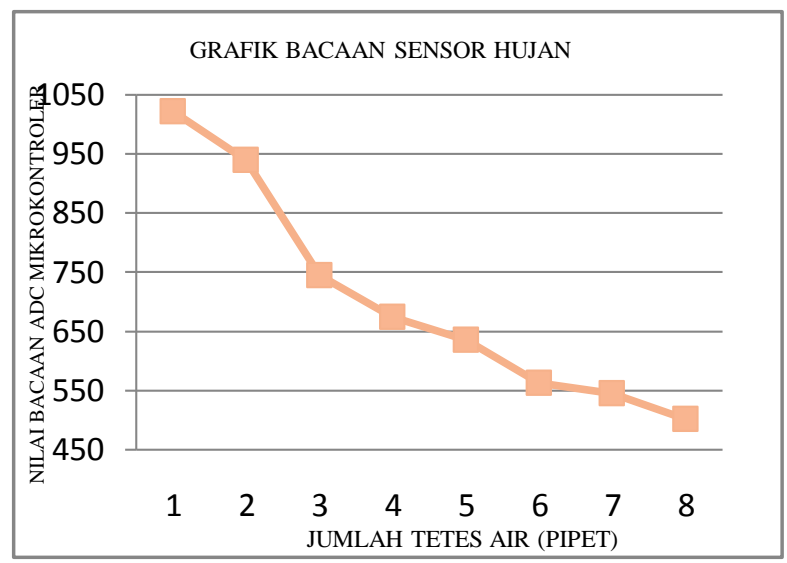

Gambar 7. Pengujian sensor hujan

Berdasarkan grafik pada gambar 7 dapat terlihat bahwa semakin banyak tetesen air yang diberikan maka nilai ADC pembacaan sensor semakin menurun, hal ini sesuai dengan datasheet sensor.

\section{Pengujian sensor DHT22}

Pengujian sensor DHT22 dilakukan dengan cara membandingkan hasil pembacaan suhu dari termometer digital terstandar dengan pembacaan sensor DHT22. Grafik pengujian sensor DHT22 dapat dilihat pada Gambar 8.

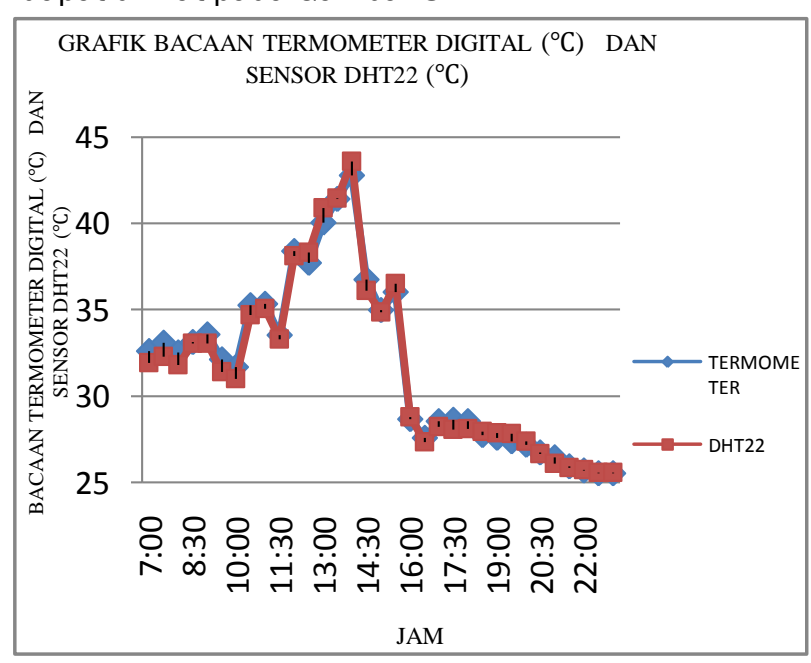

Gambar 8. Simulasi Pengujian alat kondisi hujan

Gambar 8 menunjukan grafik pembacaan sensor DHT22 dan termometer digital. Garis berwarna merah mengambarkan pembacaan sensor DHT22 sementara garis yang berwarna biru mengambarkan pembacaan termometer digital. Dari grafik terlihat bahwa pembacaan sensor DHT22 dan termometer digital memiliki selisih namun sangat dekat. Hal ini menunjukan bahwa sensor yang digunakan dapat bekerja dengan baik.

\section{Pengujian sensor cahaya}

Pada pengujian sensor cahaya kami mengunakan pencahayaan alami yakni cahaya matahari untuk melihat nilai resistansi LDR dan kepekaan sensor saat menerima cahaya. Nilai ini secara langsung dikonversi oleh mikrokontroler rsebagai nilai ADC.

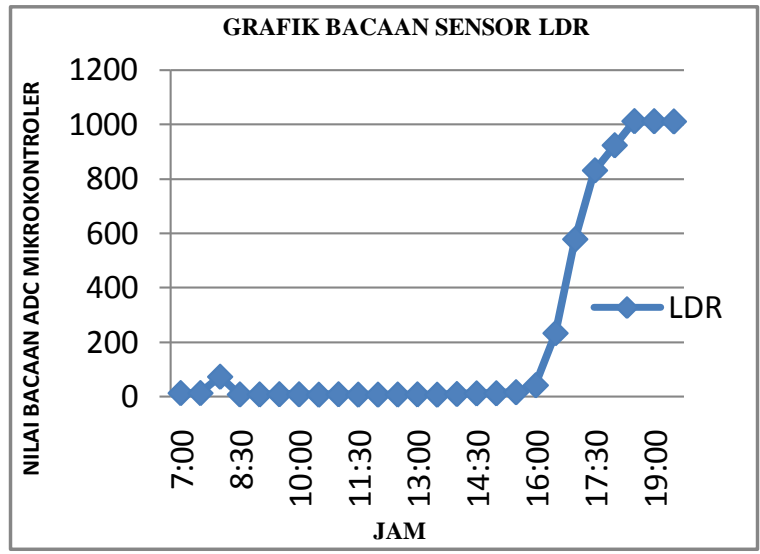

Gambar 9.Pengujian sensor cahaya

Grafik pada gambar 9 menunjukan bahwa ketika dalam kondisi terang yakni pada pagi hari hingga sore hari pukul 16:00, nilai ADC bernilai kecil yakni berkisar antara 0 - 100. Pada saat kondisi gelap, nilai ADC meningkat hingga mencapai maksimum pada pukul 19:00. Setelah rangkaian sistem kontrol atap otomatis telah dibangun dan terhubung dengan komputer kemudian dilakukan pengujian alat untuk mengetahui apakah node sensor dapat bekerja sesuai kebutuhan. Kode program telah diatur untuk kondisi pembacaan sesuai dengan perintah eksekusi program padaTabel 1 dan Tabel 2

\section{Simulasi alat secara keseluruhan}

Setelah dilakukan pengujian tiap bagian baik itu rangkaian mikrokontroler, sensor hujan, sensor suhu dan kelembaban, sensor cahaya, kipas, motor servo dan rangkaian mekanik, tahap terakhir dilakukan simulasi alat secara menyeluruh. Kondisi alat secara keseluruhan dapat dilihat pada Gambar 10.

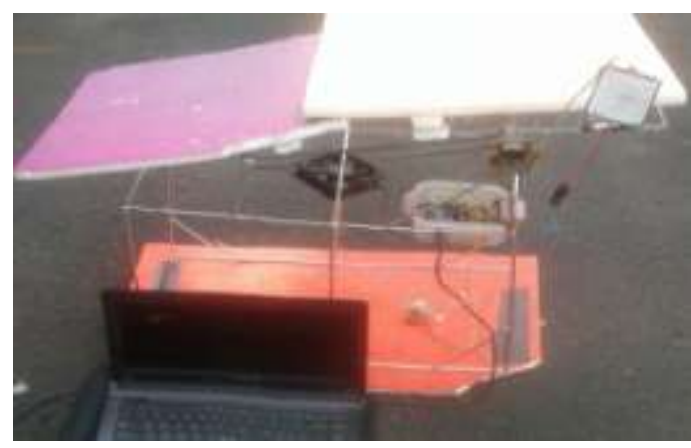

Gambar 10. Kondisi alat keseluruhan 
Tabel 1. Perintah yang dieksekusi berdasarkan pembacaan sensor hujan dan sensor cahaya.

\begin{tabular}{|c|c|c|c|}
\hline \multirow{2}{*}{ No } & \multirow{2}{*}{ Kondisi } & \multicolumn{2}{|c|}{ ATAP } \\
\cline { 3 - 4 } & & Buka & Tutup \\
\hline 1 & H\&G & & $\times$ \\
\hline 2 & H\&T & & $\times$ \\
\hline 3 & TH\&G & & $\times$ \\
\hline 4 & TH\&T & $\sqrt{ }$ & \\
\hline
\end{tabular}

Ket : $\quad \mathrm{TH}=$ Tidak Hujan $\quad \mathrm{H}=$ Hujan

$\mathrm{G}=$ Gelap

$\mathrm{T}=$ Terang

Tabel 2. Perintah yang dieksekusi berdasarkan sensor DHT22

\begin{tabular}{|c|c|c|c|}
\hline \multirow{2}{*}{ No } & \multirow{2}{*}{ Kondisi } & \multicolumn{2}{|c|}{ Kipas Angin } \\
\hline & & On & Off \\
\hline 1 & SR\&L & $\sqrt{ }$ & \\
\hline 2 & SR\&TL & $\sqrt{ }$ & \\
\hline 3 & ST \& L & $\sqrt{ }$ & \\
\hline 4 & ST \&TL & & $x$ \\
\hline & \multicolumn{3}{|c|}{$\begin{array}{l}\text { SR }=\text { Suhu Rendah } \quad T L=\text { Tidak Lembab } \\
\text { ST }=\text { Suhu TinggiL }=\text { Lembab }\end{array}$} \\
\hline
\end{tabular}

\section{Kesimpulan}

Setelah melakukan perancangan hardware dan software serta dilakukan uji coba alat dan system secara keseluruhan, maka kesimpulan penelitian ini adalah:

1. Node Sensor mampu merespon kondisi

lingkungan sekitar berupa: hujan, gelap, lembab dan suhu.

2. Mikrokontroler mampu memproses secara baik input dari masing-masing sensor, sehingga menghasilkan output berupa: membuka dan menutup atap serta mampu menghidupkan dan mematikan kipas secara otomatis.

\section{Daftar Pustaka}

Alam, M. M., \&Hamida, E. B. (2014).Surveying wearable human assistive technology for life and safety critical applications: Standards, challenges and opportunities. Sensors. 14(5) : 9153-9209.

Alausa Dele, W. S., \&Kolawole, K. K. (2013). Microcontroller Based Green House Control Device. The International Journal of Engineering And Science (IJES). 2(11) :8-12.

Damastuti, N., \& I. Syafi'i. 2016. Sistem Otomasi Atap Bangunan Pada Gudang Pengeringan Jagung Berbasis Arduino UNO. e-Jurnal NARODROID. 2(1) :111-116.

Fu, Y. H., Zhao, H., Piao, S., Peaucelle, M., Peng, S., Zhou, G., ...\& Song, Y. (2015). Declining global warming effects on the phenology of spring leaf unfolding. Nature. 526(7571) :104-107.
Fuada, S. (2013). Control System Design of Automatic Roof for Chips Drying Device (Software Version). Int. J. of Scientific \& Engineering Research.(IJSER). 4(7) :14081412.

Golmohammadi, R., Eshaghi, M., \&Khoram, M. R. (2011).Fuzzy Logic Method for Assessment of Noise Exposure Risk in an Industrial Workplace. International Journal of Occupational Hygiene. 3(2) :49-55.

Hendriawan, K. 2015. AtapOtomatis Sensor Suhu, Air Dan Tenaga Surya (Alas Susu).Electronics, Informatics, and Vocational Education. 1 (1): 46-52

Jochem, A., Höfle, B., Rutzinger, M., \& Pfeifer, N. (2009).Automatic roof plane detection and analysis in air borne lidar point clouds for solar potential assessment. Sensors. 9(7) :52415262.

Kurnia, M., A. Warsito., \& A. C. Louk.2016. Perancangan Alat Pembuka Dan Penutup Atap Penjemur Gabah Secara Otomatis Dengan Menggunakan Arduino UNO Berbasis Mikrokontroler ATmega328. Jurnal Fisika Sains dan Aplikasinya. 1(1) : 18-24.

Lwin, H. H., Khaing, A. S., \&Tun, H. M. (2016).Automatic door access system using face recognition. International Journal of Scientific \& Technology Research. 4(6) : 210221.

Mosey, H. I. R. (2017). Pengembangan Purwarupa Node Multi Sensor Pemantau Parameter Cuaca Berbasis Mikrokontroler.Jurnal MIPA Unsrat Online, 6(1), 21-25.

Mowad, M. A. E. L., Fathy, A., \& Hafez, A. (2014). Smart home automated control system using android application and microcontroller. International Journal of Scientific \& Engineering Research. 5(5) : 935-939.

Mufida, E., \& A. Abas.2017. Alat Pengendali Atap Jemuran Otomatis Dengan Sensor Cahaya Dan Sensor Air Berbasiskan Mikrokontroler ATmega16. Informatics for Educators and Professionals. 1(2) : 163-172.

Nusyirwan, N. 2014.Kajian Pengering Gabah Dengan Wadah Pengering Berbentuk Silinder Dan Mekanisme Pengaduk Putar. Cylinder: Jurnal IImiahTeknik Mesin. 1(2) : 45-52.

Saad, M., Farij, A., Salah, A., \&Abdaljalil, A. (2013).Automatic street light control system using microcontroller. Mathematical Methods and Optimization Techniques in Engi(ISBN). 978(960)92-96.

Suleman, M. 2010. Replika Sistem Atap Otomatis Untuk Pelindung Benda Terhadap Hujan Berbasis Mikrokontroler AT89S52 .http://www.gunadarma.ac.id/library/articles/ graduate/computer science/2010/Artikel_21105095.pdf [2010].

Susandi, A., I. Herlianti., M. Tamamadin., \& I. Nurlela. (2008). Dampak perubahan iklim terhadap ketinggian muka laut di wilayah 